\title{
RECURSOS EDUCACIONAIS ABERTOS PARA O ENSINO DE LÍNGUA MATERNA NO ENSINO MÉDIO
}

Elena Maria Mallmann Juliana Sales Jacques

Mara Denize Mazzardo ${ }^{(*)}$

\section{CIRCULANDO ENTRE PALAVRAS, TECEMOS NOSSAS CONSIDERAÇÕES INICIAIS...}

Entre coisas e palavras - principalmente entre palavras - circulamos. [...]
Entre palavras e combinações de palavras circulamos,
vivemos, morremos, e palavras somos [...]." (Carlos Drummond de Andrade, In: Poesia e prosa, 1988).

Os dizeres de Carlos Drummond de Andrade expressam, com maestria, o quão simbólicos somos enquanto seres humanos. Significamos sempre através da linguagem, seja ela verbal (palavras, combinações de palavras), não verbal (coisas, gestos) ou paraverbal (entonação, ritmo, cadência melódica). Enquanto a língua é um sistema de signos, uma unidade sonora e cultural que representa uma nação, a linguagem é o movimento, a articulação dos signos que nos constituem e legitimam a comunicação em diferentes espaços e contextos. A língua, portanto, é parte da linguagem, mas esta é dependente daquela.

Toda língua tem sua gramática justamente para que a linguagem verbal aconteça, ou seja, para que a comunicação, através de palavras e suas combinações, torne-se real, autêntica. Pensemos, então, sobre o ensino da língua materna sem dissociar o objeto teórico da linguística (a língua) do objeto empírico (a linguagem). Parece-nos que o ensino tradicional da língua materna (neste caso, o português do Brasil) a idealiza como objeto teórico desvinculado de comunicação, interação, discursividade; não a coloca em movimento. Ao contrário, pelas práticas de ensino, a limita a um conjunto de regras gramaticais. Todavia, partilhando da reflexão de Almeida et al. (2006), questionamo-nos: a capacidade de saber o sujeito da oração faz-nos ser sujeitos da nossa própria história?

\footnotetext{
${ }^{(*)}$ Elena Maria Mallmann. Professora doutora do Departamento Administração Escolar (ADE) da Universidade Federal de Santa Maria (UFSM), RS. E-mail: elena.ufsm@gmail.com.

Juliana Sales Jacques. Professora substituta na área de Metodologia, didática e práticas do Ensino da Língua Portuguesa do Centro de Educação da UFSM - Santa Maria, RS - Brasil. E-mail: juletras.jacques@gmail.com.

Mara Denize Mazzardo. Doutoranda em Educação, especialidade em Educação a Distância e Elearning, na Universidade Aberta (UAb) de Portugal. Professora da Rede Pública Estadual (RS). E-mail: maradmazzardo@gmail. com.
} 
Partindo dessa reflexão, vislumbramos um ensino de língua materna cujas práticas não dissociem forma e função de uso. Que o foco seja o ensino global da língua, pois é a sua totalidade que nos constitui. Nesse sentido, argumentamos que a (co)autoria de Recursos Educacionais Abertos (REA) no contexto do Ensino Médio é uma possibilidade inovadora para o compartilhamento de materiais na dimensão interacional. Ademais, desafiam os professores à ampliarem suas referências para além dos livros didáticos no processo de planejamento e seleção de materiais didáticos.

REA, ou Open Educational Resources (OER), segundo parâmetros da Unesco, são materiais de ensino e pesquisa, digitais ou impressos, que possuem licenças abertas permissivas de adaptações. Ao (co)autorarmos REA, nessa perspectiva educacional, potencializamos além do compartilhamento de propostas e práticas que se sustentem no uso real da língua, "a abertura legal e a abertura técnica" (AMIEL, 2014, p. 198) para que todos os professores do Ensino Médio possam (co)autorar, adaptando os materiais às especificidades do contexto e público. Nessa perspectiva, vislumbra-se possibilidades concretas de mesclar materiais impressos, como o livro didático, com materiais digitais.

Diante disso, para compor a síntese reflexiva dos ciclos espiralados de pesquisa-ação, analisamos REA de língua portuguesa, produzido durante práticas formativas no formato Small Open Online Course (SOOC). Esse curso denominado "REA: Educação para o futuro", tem como participantes professores do Ensino Médio de diversas áreas do conhecimento, inclusive do componente curricular de língua portuguesa, das redes públicas estadual e federal do Rio Grande do Sul. Desenvolvemos as atividades em parceria com a Universidade Aberta de Portugal (UAb) e a Universidade Federal de Santa Maria (UFSM), objetivando estudar, pesquisar, dialogar sobre REA para promover, através da (co)autoria de materiais abertos, mais autonomia didático-pedagógica, aos professores, no processo formativo na educação de nível médio.

Como o curso abrange várias áreas do conhecimento, muitos REA foram produzidos. Todavia, nosso recorte temático é o ensino da língua materna na dimensão interacional, por isso, discutimos e analisamos um REA produzido na área de língua portuguesa. Assim, nas páginas seguintes deste artigo, dialogamos sobre os caminhos para o ensino-aprendizagem da língua materna visando explicitar seu potencial interativo e comunicativo. Argumentamos que os REA, diante das possibilidades de adaptações, são materiais potencializadores de práticas mais autênticas e coerentes com os diferentes contextos educacionais. Apresentamos o caminho metodológico e analisamos, como resultado de pesquisa-ação, o REA de ensino da língua materna produzido como planejamento didático. Toda a nossa escrita move-se pela inquietação: em que medida podemos 
potencializar práticas de ensino reais e autênticas da língua materna no Ensino Médio com a integração de REA? Nesse movimento reflexivo, circulando entre palavras e combinando-as, tecemos nossos dizeres.

\section{COMBINANDO PALAVRAS SIMBOLIZAMOS NO/O MUNDO: UM OLHAR SOBRE O ENSINO DA LÍNGUA MATERNA}

Quais equívocos têm perpassado o caminho do ensino da língua materna? No meio do caminho de Drummond (1967), tinha uma pedra e jamais, afirmou o poeta, ele esqueceria desse acontecimento na vida de suas retinas tão fatigadas. Coincidentemente, nas aulas de língua portuguesa, também há uma pedra no meio do caminho, afirma Antunes (2003). O ensino mecanicista limitado à memorização pura e descontextualizada de regras gramaticais, na concepção da autora, é a pedra que precisa ser removida, superada para que de fato contemplemos o potencial interativo e comunicativo da nossa língua. Práticas arraigadas nessa perspectiva de ensino da língua geram equívocos na compreensão do processo formativo dos estudantes no Ensino Médio, trazendo outras pedras para o meio do caminho.

Cabe-nos, no planejamento das práticas pedagógicas, questionar: se nossos estudantes são falantes nativos, o que precisam aprender na disciplina de língua portuguesa? O que temos que ensinar? Qual o objetivo, a finalidade de ensinar o que ensinamos? Ora, o estudante já transita pela língua materna; já se comunica em diferentes contextos sociais. O objeto de estudo, portanto, não é um desconhecido, muito embora tenhamos escutado, por vezes, nossos estudantes alegarem que não sabem língua portuguesa. É a pedra no meio do caminho! É o abismo existente, muitas vezes, entre as práticas sociais de uso da língua no cotidiano e as práticas ensinadas na escola.

"A escola ensina os alunos a ler e a escrever orações e períodos, e exige que interpretem e redijam textos" (FIORIN, 2014, p. 9). Como requerer interpretação e produção textual dos estudantes se estão habituados a exercícios puramente de metalinguagem? Ademais, como requer práticas de (co)autoria dos professore no Ensino Médio? Tanto professores quanto estudantes estão, muitas vezes, inseridos em práticas reducionistas de estudo, ensino e uso da língua. Atividades metalinguísticas são necessárias, mas é preciso mudar o seu percurso. Não podem ser dissociadas de atividades linguísticas e epilinguísticas. Isso porque o conhecimento descritivo, sistemático da língua converge para o desenvolvimento da competência linguística se posto em reflexão nas práticas sociais da língua. No momento em que proporcionamos "[...] exercício pleno, circunstanciado, intencionado e com intenções significativas da própria linguagem [...]" (FRANCHI, 1988, p. 35) - atividades linguísticas - e "prática que opera sobre a própria linguagem, 
compara as expressões, transforma-as, experimenta novos modos de construção canônicos ou não, brinca com a linguagem, investe as formas linguísticas de novas significações" (FRANCHI, 1988, p. 36) - epilinguística -, interligamos forma e função no uso da língua.

Trabalhamos forma e função da língua combinando palavras, explorando-as, ressignificando-as. Ao fazê-lo, simbolizamos no/o mundo. Somos seres simbólicos (ORLANDI, 2004), pois (re)significamos através da linguagem. O ser simbólico denota representar algo, expressar e expressar-se, constituir-se na e pela linguagem (verbal, não verbal e paraverbal). Nesse movimento, precisamos avançar para além da representação no/do mundo, precisamos nos/o transformar, criar/autorar e cocriar/autorar. E que subsídios a escola nos fornece para fazê-lo? De fato significaremos, representando, explicando e (nos)transformando o/no mundo se a linguagem for um lugar de interação social; um lugar em que produzamos e negociemos sentidos no curso da interação, tanto em gêneros textuais orais quanto escritos.

Produzir e negociar sentidos requerem uso autêntico, real e social da língua. E, "se toda ação pedagógica é uma ação política, com muito maior razão o é optar por uma concepção de ensino que consideramos desalienante, formadora e crítica” (RICHTER, 2000, p. 10). Isto é, que potencialize a formação de leitores e produtores de textos (orais e escritos) mais autônomos, críticos e reflexivos; mais perceptivos, por exemplo, das coerções impostas pelos veículos midiáticos de comunicação, que induzem à formação em massa de opinião única, à luz de um teor ideológico, político, axiológico. Para tanto, a ação pedagógica precisa, como argumenta Richter ( 2000, p. 95), “ensinar a pescar", ou seja desenvolver nos estudantes a capacidade "de aprender [...] de assimilar e aplicar estratégias de produção crítica do conhecimento".

Por isso, atividades de metalinguística, linguística e epilinguística, que abarquem forma e função, são indissociáveis na dimensão interacional da linguagem. De que vale a sabedoria gramatical (normativa, descritiva) dissociada das sabedorias semântica, pragmática? "Entre o porque e o por quê há mais bobagem gramatical do que sabedoria semântica." (Millôr Fernandes, apud ANTUNES, 2003, p. 19). O dizer de Millôr Fernandes, publicado como epígrafe na obra de Antunes (2003), fortalece nosso argumento: a memorização mecânica, a "decoreba" de regras gramaticais (nos princípios da teoria normativa) através de exercícios exaustivos de repetição em nada agrega para o desenvolvimento da capacidade linguística e discursiva. Essas práticas não são coerentes com os princípios estéticos, políticos e éticos delimitados pelas Diretrizes Curriculares Nacionais para o Ensino Médio (BRASIL, 2012), no Art. 12, quando afirma que o currículo do Ensino Médio deve garantir ações que promovam, dentre outras, “c) a língua portuguesa como instrumento de comunicação, acesso ao conhecimento e exercício da cidadania (p. 04). Assim, cabe 
sempre problematizar se promovemos uso, reflexão e uso, como os próprios documentos legais para o ensino da língua portuguesa na área de Linguagens, Códigos e suas Tecnologias (BRASIL, 1997; 2000a e b; 2006) vendo orientando há pelo menos uma década.

Notemos que à pedra do ensino tradicional, mecanicista, agregam-se muitas outras no meio do caminho. Buscar ensino que trabalhe a língua materna como organismo vivo, cultural, dinâmico, dialógico é um dos caminhos possíveis para superação dos desafios no Ensino Médio. Exploremos todas as funções comunicativas da linguagem - referencial, emotiva, apelativa, poética, fática, metalinguística -, envolvendo nossos estudantes em movimentos interativos de produção e negociação de sentidos. Assim, o saber normativo, sistemático, formal da língua estará interligado ao saber funcional, estratégico, de uso. Pressupomos, desse modo, práticas pedagógicas que envolvam as quatro habilidades linguísticas (falar, ouvir, ler e escrever). Isso porque, como seres sempre dialógicos (BAKHTIN, 2011), a competência linguística é de fato legitimada se, em diferentes contextos, fazemos uso da palavra e suas combinações para produzir e negociar sentidos, seja na modalidade oral, seja na modalidade escrita.

\subsection{Falar, ouvir, ler e escrever: palavras enunciamos e palavras somos}

Estamos sempre envoltos pelo universo da linguagem. Aprendemos a nos comunicar desde os primeiros balbucios, as primeiras palavras, as frases incompletas. À medida que nos desenvolvemos interagindo com o outro, tornamo-nos capazes de formular, pronunciar frases, sentenças mais complexas. A psicolinguística dá conta de explicar e discutir o processo de aquisição da linguagem. Não é o nosso foco de estudo neste artigo. Todavia, iniciamos este tópico com essa exposição justamente para endossar o que vimos discutindo ao longo do texto: se em todos os domínios sociais, ambientes externos à escola utilizamos a língua materna fazendo-nos compreender na interlocução, por que na escola não vemos a linguagem como lugar de interação?

Sinais de mudança, como já argumentamos, precisam emergir, em grande escala, nesse cenário marcado historicamente por práticas focadas apenas no aspecto normativo, descritivo da língua. Muito se tem investido, desde a década de 1980, em pesquisas e publicações que trazem para a pauta o ensino de língua materna que vise, efetivamente, à interação comunicativa. Estudos vinculados a projetos de pesquisa, de extensão, de iniciação à docência, entre outros abarcam o todo constitutivo da língua: a semântica, a pragmática, a sociolinguística, a psicolinguística etc. Todavia, temos muito que avançar no cotidiano da sala de aula.

Há muitas pedras a serem removidas! Comecemos a removê-las ampliando o repertório de gêneros textuais. Parece-nos, pelas práticas vivenciadas, que na escola impera um único gênero 
textual: a redação escolar; e uma única tipologia: a dissertativo-argumentativa. Se nos comunicamos através dos gêneros textuais, por que priorizar apenas a redação escolar, que como o própria nomenclatura enuncia, transita exclusivamente no domínio escolar? Sabemos que as avaliações externas priorizam tal gênero, mas o papel da escola, como orientam os Parâmetros Curriculares Nacionais para o Ensino Médio, é formar cidadãos, prepará-los para viver em sociedade, inserindoos "como cidadão em um mundo letrado e simbólico." "No mundo contemporâneo, marcado por um apelo informativo imediato, a reflexão sobre a linguagem e seus sistemas [...] é mais do que uma necessidade, uma garantia de participação ativa na vida social, a cidadania desejada." (BRASIL, 2000a, p. 20).

Garantir a participação ativa na vida social é, à luz da dimensão interacional da linguagem, desenvolver, ou melhor, ampliar a competência linguística no uso oral e escrito da língua materna. Fazemos isso explorando gêneros textuais de ambas as modalidades. Por mais que alegue ser difícil definir conceitualmente gêneros textuais, Marcusch (2008) os considera entidades sociodiscursivas, formas de ação social dotadas de funções. A essas formas e funções comunicativas que nós, professores, precisamos nos deter. Seja na oralidade, seja na escrita o estudante precisa "[...] adequar-se ao gênero, planejar o texto, organizar sua sequência, selecionar a variedade linguística, dialogar com os discursos que circulam socialmente.” (FARACO, 2005, p. 8). Ao fazê-lo, estará, ao mesmo tempo, trabalhando com aspectos notacionais, linguísticos, semânticos, discursivos da língua.

A prática de produção textual, ou seja, o trabalho com a escrita, é corriqueira no cotidiano da sala de aula, mesmo que, muitas vezes, produção apenas do gênero redação escolar. Entretanto, de que modo é planejada, é orientada? Antunes (2003, p. 44) defende que "a escrita, como toda atividade interativa, implica relação cooperativa entre duas ou mais pessoas". É dotada de intencionalidade e cumpre determinado objetivo. Nesse sentido, ao encontro do pensamento da autora, o texto escrito precisa ser um lugar de encontro e interação entre interlocutores. Por isso, produzir um texto pressupõe um leitor do outro lado, seja ele real ou virtual. Se temos algo a dizer, a enunciar pressupomos alguém para ler e interagir conosco, produzir sentidos.

Para tanto, precisa ser uma prática planejada, com tempo didático adequado para planejamento, escrita e reescrita - etapas destacadas por Antunes (2003). No momento da reescrita, o estudante precisa refletir não somente sobre a forma, elementos notacionais, mas sobre os efeitos de sentidos que sua escrita virá a produzir no leitor. Se de fato os fatos narradas, as informações descritas, expostas, as argumentações temáticas estão coerentes como a ideia, o objetivo da escrita. 
Por isso, leitura e escrita andam juntas, uma vez que somos os primeiros leitores de nossos textos. Precisamos, o tempo todo, ir e vir na escrita, mantendo a essência da textualidade.

Ao abordarmos a leitura, mencionamos outra habilidade linguística. Como é explorada essa habilidade na escola? Ensinar a ler requer muitas estratégias. A leitura é muito mais do que decodificação. É, sobretudo, inferenciação. Sem compreender os implícitos do texto, as coisas que estão nas entrelinhas, não há interpretação, não inferenciamos nada. Ler um texto implica interação com autor e com o próprio texto, a fim de que sentidos sejam produzidos. Sentidos que não estão no texto, mas que se constroem a partir dele, como argumenta Koch (2014), ou seja, a partir da interação entre leitor, texto e autor. O texto assemelha-se ao iceberg, "possui apenas uma pequena superfície exposta e uma imensa área subjacente. Para se chegar às profundezas do implícito e dele extrair um sentido, faz-se necessário o recurso aos vários sistemas de conhecimento e a ativação de processos e estratégias cognitivas e interacionais.” KOCH (2014, p. 30).

Para que ocorra essa interação entre leitor, texto e autor, ao produzirmos um texto, ou seja, ao autorarmos, temos que fornecer pistas que denotem o "quer dizer". Isso porque o leitor produzirá um sentido ativando diversos tipos conhecimentos, inclusive e essencialmente, o ilocucional - o conhecimento sobre o que o autor está defendendo, narrando, descrevendo, expondo etc. Esse conhecimento não depende somente do leitor, mas também do autor. O texto, como argumenta Antunes (2003), tem que funcionar como um mapa direcionando o leitor à produção de sentidos. Essa tem de ser preocupação latente do autor no momento de produção.

Até aqui temos argumentado sobre a produção escrita, mas a produção de sentidos é inerente à oralidade também. E que práticas de oralidade temos vivenciado nas escolas? Parece-nos que, em virtude de a fala ser anterior à escrita, não há ênfase, não há por que explorá-la como prática social. Essa é outra pedra no meio do caminho do ensino da língua materna. Muitas vezes, os estudantes têm habilidade para dissertar, argumentar sobre uma ideia no texto escrito, mas não o fazem no texto oral. Por que essa dificuldade? Arriscamo-nos a dizer que há fragilidade no desenvolvimento das habilidades de ouvir e falar. Arriscamos até a afirmar que pouco são (ou não são!) trabalhadas. Qual é o papel da escola, diante disso? A reposta, equematizamos na figura 1, a partir das concepções de Antunes (2003). 
Figura 1: Trabalhando as habilidades ouvir e falar

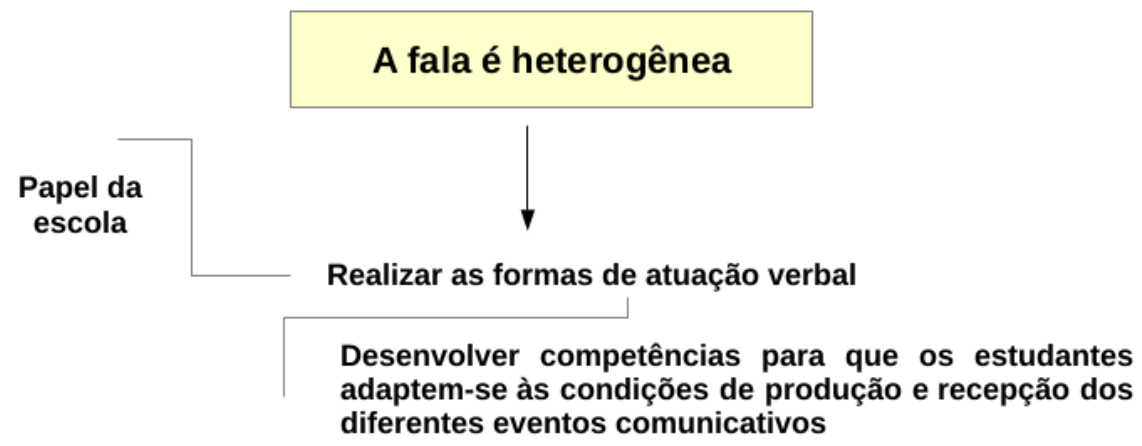

Fonte: As autoras, com base em Antunes (2003).

Tratamos aqui, portanto, de uma oralidade planejada, orientada de acordo com o contexto do evento comunicativo. $\mathrm{O}$ estudante, enquanto cidadão, precisa desenvolver a capacidade de realizar formas de interação verbal, atuar e autorar através da fala e da escuta, em diferentes domínios sociais. Para tanto, aprender o que falar no momento de interação, quando falar, que recursos linguísticos e discursivos utilizar é desenvolver a habilidade da fala, como também da escuta. Isso porque, utilizando o exemplo da argumentação na interação oral, enquanto autores - produtores de texto -, ao defendermos uma ideia, precisamos primeiro ouvir o interlocutor. Nesse sentido, práticas que explorem a oralidade precisam ser ampliadas, melhoradas nas aulas de língua portuguesa, a fim de que propositemos a formação global da competência comunicativa. Isso implica também trabalhar as variedades linguísticas do português falado.

O ensino da língua padrão é preciso, é essencial. O embate introduzido é contra a já consagrada expressão "erro de português". Nesse engajamento, Bortoni-Ricardo (2004) argumenta que os chamados "erros" têm explicação no próprio sistema evolutivo da língua. Por isso, na escrita e na oralidade planejada, monitorada, ou seja, em situações linguísticas mais formais, a língua padrão é essencial. Todavia, em situações menos monitoradas, como interações entre amigos, familiares, as variedades do português falado precisam e devem ser respeitadas. Esse é um ponto importante, ou melhor, necessário a ser trabalhado no ensino da língua materna, a fim de combater toda e qualquer discriminação pela linguagem.

Notemos que a linguagem como lugar de interação social requer bem mais que aprender a identificar os termos de uma oração, a decorar as nomenclaturas e as regras gramaticais. É preciso saber o que fazer com tudo isso. A leitura, a escrita, a fala e a escuta estão presentes em todas as disciplinas, em todas as áreas do conhecimento. O estudante pode e deve desenvolver a competência linguística, discursiva, comunicativa não só nas aulas de português, mas sim em todas 
as demais. Todavia, é papel, não exclusivamente, mas essencialmente, do professor de língua materna potencializar essa competência. Por isso, a produção de REA é importante, pois viabiliza o compartilhamento de práticas didáticas abertas para utilização e adaptação em diferente contextos educacionais, de acordo com as necessidades de ensino da língua materna. Diante disso, no próximo tópico, discorremos sobre REA e suas potencialidades.

\section{EM MOVIMENTO CÍCLICO ENTRE PALAVRAS, (CO)AUTORAMOS REA}

O índice de Desenvolvimento da Educação Básica (Ideb) “evidencia que, entre os níveis da Educação Básica, o Ensino Médio é o que está em pior situação” (MOTA, 2016, p. 1). Para responder aos baixos índices de aproveitamento do Ensino Médio vários aspectos são relevantes, como as políticas públicas, a proposta curricular, as práticas pedagógicas, a infraestrutura das escolas, o acompanhamento e incentivo dos pais, a formação e valorização dos professores, a integração das tecnologias no processo de ensino e aprendizagem e os materiais didáticos.

Mas, o que são materiais didáticos e por que são relevantes no processo de ensinoaprendizagem? Existe diferença entre materiais didáticos e recursos educacionais? Mallmann e Nobre (2015, p. 624) definem recurso educacional como "um material didático organizado, intencional, sistemático e de caráter formal para apoio ao processo ensino-aprendizagem. Diferencia-se de outros recursos por ter função expressamente didático-metodológica vinculada a determinado currículo". O conceito apresentado iguala o significado dos termos ao considerar que um recurso educacional é um material didático. Desta forma, consideramos que recurso educacional e material didático são designações que possuem o mesmo objetivo, que é possibilitar, contribuir para que ocorra aprendizagem. Freitas $(2007$, p. 21) define materiais e equipamentos didáticos (conhecidos também por recursos e tecnologias educacionais), como "todo e qualquer recurso utilizado em um procedimento de ensino, visando à estimulação do aluno e à sua aproximação do conteúdo." Incentivar a aprendizagem, dinamizar a aula e despertar a curiosidade dos estudantes sobre os conteúdos são algumas funções do material didático, destacadas pela autora.

Além dos materiais impressos, como os livros didáticos, os professores do Ensino Médio estão começando a utilizar materiais didáticos digitais como textos e imagens isoladas, animações, simulações, recursos multimídia, hipermidiáticos. Os REA "são materiais de ensino, aprendizagem e investigação, em qualquer suporte ou mídia, digital ou não, que estão sob domínio público ou são disponibilizados com licença aberta que permite o acesso, uso, adaptação e redistribuição gratuita por terceiros, sem restrição ou com poucas restrições” (UNESCO, 2012. p. 1). O fator que diferencia um REA dos outros recursos educacionais é a disponibilização sob licenças abertas, que 
possibilitam o livre acesso, o compartilhamento, reuso, remix e a adaptação para outros contextos, sem necessidade de solicitar autorização ao autor ou detentor dos direitos autorais (BUTCHER, 2011; SANTOS, 2012). São exemplos de REA: cursos completos, materiais de cursos, módulos, livros didáticos, livros, capítulos de livros, artigos de pesquisa, testes, planejamentos de atividades didáticas, vídeos, recursos multimídia, animações, simulações, infográficos, mapas, imagens, áudios, jogos, software (UNESCO, 2015).

Sobre os aspectos que caracterizam a abertura dos REA, Wiley (2014), definiu os 5 Rs de abertura:

- Reter (Retain): direito de fazer e possuir cópias dos recursos.

- Reutilizar (Reuse) - direito de usar o conteúdo de formas variadas.

- Rever (Revise): direito de adaptar, ajustar, modificar ou alterar o conteúdo.

- Remix (Remix): direito de combinar o conteúdo original ou adaptado com outro ou outros conteúdos abertos para criar um novo recurso.

- Redistribuir (Redistribute): o direito de compartilhar cópias do conteúdo original, revisados e/ou remixados.

Os cinco "Rs" da abertura caracterizam os REA, ampliam as possibilidades pedagógicas, potencializam o reuso, a autoria de material didático aberto pelos professores e aumentam a produção e compartilhamento de REA. Porém, para efetivar os 5Rs, os recursos devem estar disponibilizados com licenças abertas, serem de domínio público ou possuírem termo de uso que permita a produção de obra derivada. Além da abertura legal, é necessário abertura técnica, a qual é caracterizada pelo uso de padrões reconhecidos e formatos abertos (AMIEL, 2014), que possibilitem a edição do recurso.

As licenças abertas mais conhecidas e utilizadas são as do Creative Commons, nas quais alguns direitos são reservados, contrapondo o Copyright de "todos os direitos reservados". Com as licenças Creative Commons o autor define as permissões com as quais disponibilizará as suas obras (Quadro 1).

Quadro 1. licenças Creative Commons: ícones, e tipos de licenças

\begin{tabular}{|l|l|}
\hline Ícone & \multicolumn{1}{|c|}{ Tipo de Licença } \\
\hline (2) & $\begin{array}{l}\text { Domínio Público (CC0) - Não há direitos reservados. Autor renuncia a todos os } \\
\text { direitos de autor e direitos conexos de que seja titular sobre o trabalho, tornando de } \\
\text { Domínio Público. }\end{array}$ \\
\hline
\end{tabular}




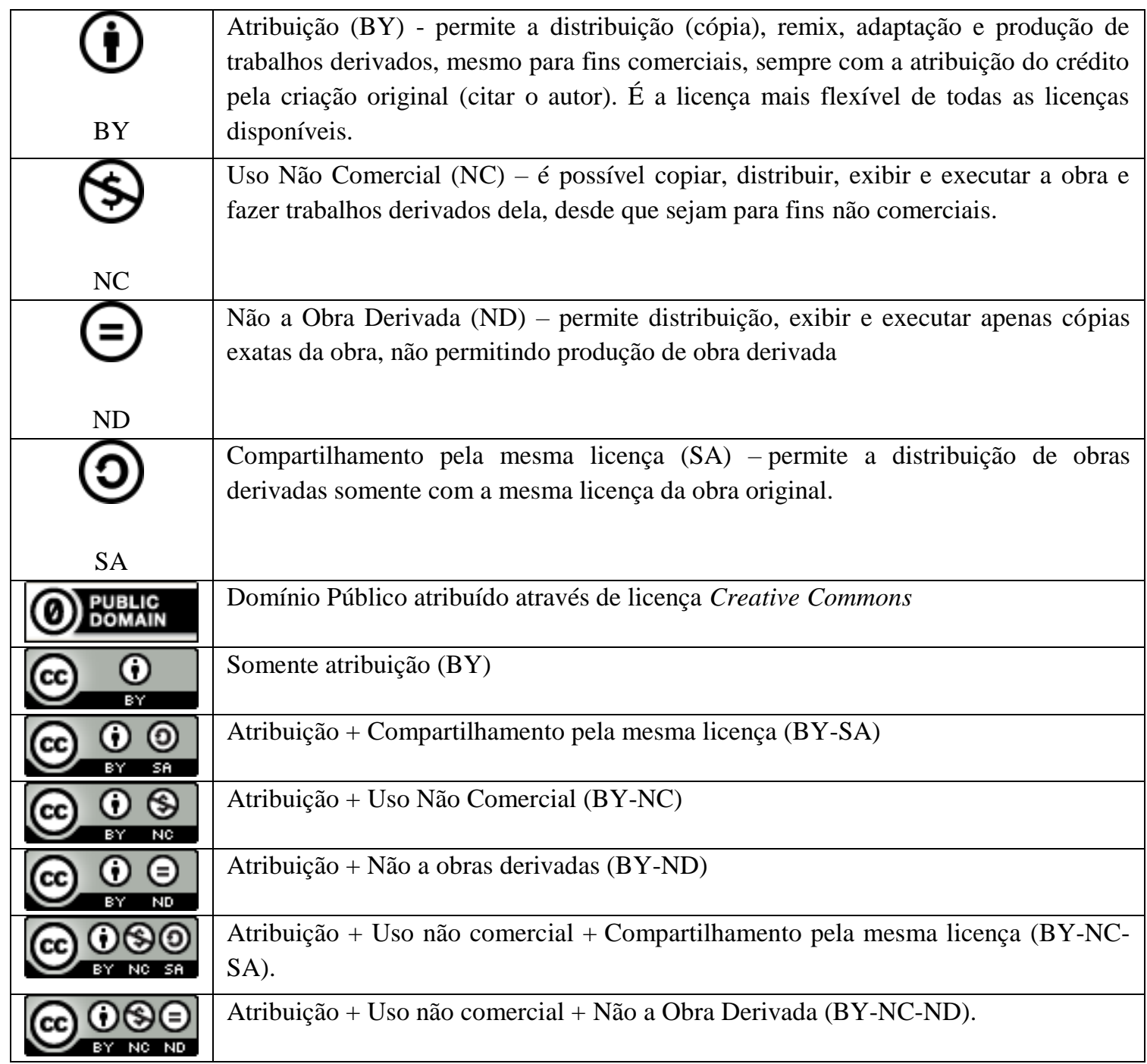

Fonte: As autoras, com base nos dados e imagens do Creative Commons: https://creativecommons.org/licenses/

As licenças Creative Commons incentivam o compartilhamento e "quando as pessoas compartilham sua criatividade e conhecimento com o outro, coisas incríveis podem acontecer" (SEBRIAM e GONSALES, 2016, p. 40).

Para identificar os REA, além do conhecimento sobre as licenças abertas, é necessário ter conhecimentos básicos sobe a Lei de Direitos Autorais (9610/98) e sobre as Obras de Domínio Público.

\subsection{Coautorando e Autorando REA}

A filosofia de compartilhamento dos REA provoca um repensar sobre as concepções de uso, produção e distribuição dos materiais didáticos. Os professores, além de reter, reusar, remixar e distribuir, podem: adaptar os recursos aos contextos e necessidades dos estudantes, personalizando o ensino; produzir recursos em vários formatos, não ficando restrito aos materiais impressos ou aos livros didáticos de determinadas editoras comerciais; produzir REA originais para ampliar e 
diversificar os materiais didáticos. Desta forma, os professores avançam da condição de consumidores para a de (co)autores de materiais didáticos. Tezza (2002) destaca que a condição de inacabamento dos materiais didáticos, a necessidade de realizar atualizações constantes dos conteúdos e o conhecimento dos problemas de estudantes reais, são argumentos que qualificam o professor para ser autor de materiais didáticos.

Um diferencial dos REA é a possibilidade de remixar e adaptar, isto é, produzir uma obra derivada. Adaptar consiste em, quando for necessário, realizar alterações no recurso para que possa ser integrado nas práticas didáticas, tais como: atualização de informações, agregar ou suprimir conteúdos, utilizar outra mídia para representar os conteúdos, tradução ou outras alterações oriundas da criatividade do professor e/ou necessidade do contexto.

Os resultados de processos cíclicos de pesquisa-ação têm evidenciado que o conhecimento dos professores do Ensino Médio, sobre REA, ainda é incipiente por se tratar de um movimento recente no cenário nacional e internacional. Assim, a adaptação e produção de REA são atividades desafiadoras porque demandam conhecimentos sobre os REA (saber identificar e onde encontrar), sobre as licenças abertas e os direitos autorais. Desse modo, torna-se necessário desenvolver e aprimorar a fluência tecnológico-pedagógica para os trâmites didático-metodológicos, bem como operações em repositórios e manipulação das tecnologias. Assim, organizamos orientações para adaptar e produzir REA como uma das ações concretas de pesquisa-ação nas práticas formativas durante o SOOC "REA: Educação para o futuro" com professores do Ensino Médio:

1. O recurso precisa ter uma licença que permita a produção de obra derivada (abertura legal) e um formato que possibilite a edição (abertura técnica). Essa é uma grande pedra no caminho da adaptação de REA, pois os recursos com licenças que permitem produção de obra derivada são os de menor número nos repositórios e as licenças nem sempre são identificadas com facilidade. Recursos com direitos autorais, mas com termos de uso ou cessão, que permite produção de obra derivada e obras de domínio público também podem ser adaptadas.

2. Definir as alterações e selecionar os recursos que serão agregados - todos os recursos agregados devem ter licenças que permitam a produção de obra derivada ou ser de autoria própria.

3. Selecionar os software que serão utilizados, dando preferência para os software livre e produção de recursos em formatos abertos.

3. Informar que é um REA adaptado, citar o autor original e o autor da adaptação, o endereço do REA original, o do REA adaptado e referenciar todos os recursos agregados. 
4. Observar a compatibilidade das licenças ${ }^{1}$ e definir a licença do REA adaptado

5. Compartilhar o REA adaptado para manter a corrente de reter, reusar, revisar (adaptar), remixar e redistribuir.

$\mathrm{Na}$ figura 2 sistematizamos em formato gráfico um roteiro identificando etapas desde a seleção até a implementação das adaptações de REA.

Figura 2. Roteiro para selecionar e adaptar REA

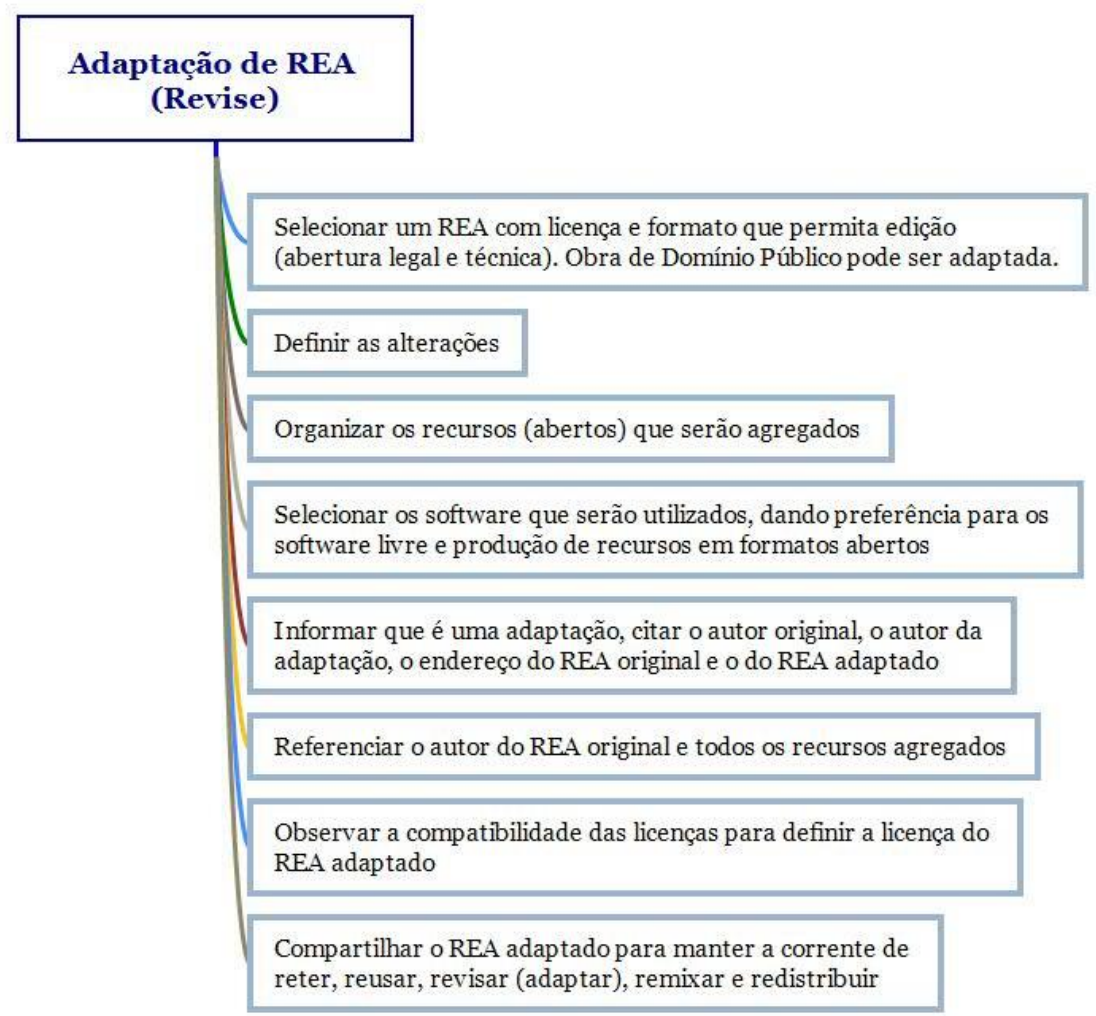

Fonte: As autoras.

A produção de um REA original também é desafiadora, envolve vários conhecimentos e o cuidado para não infringir os direitos autorais. Para orientar o processo organizamos um pequeno roteiro:

1 Definir o tema e organizar o conteúdo. O conteúdo deve ser de autoria própria, organizado de forma acadêmica (com citações diretas e indiretas), ser de autoria própria, ter licenças abertas ou termo de cessão de direito que permitam a produção de obra derivada ou ser de domínio publico.

2. Selecionar as mídias que serão integradas no recurso, as quais devem ser de autoria própria ou abertos.

\footnotetext{
${ }^{1}$ Verificar compatibilidade das licenças em <http://wikieducator.org/OER_Handbook/educator_version_one/License/ License compatibility>.
} 
3. Definir o formato e selecionar os software de autoria para produzir. Optar por software livre e formatos abertos. As sugestões de recursos são texto, vídeo, imagem, áudio, animação, simulação, produção multimídia ou hipermidiática, infográficos e linhas de tempo.

4. Definir a licença e inserir no recurso.

5. Disponibilizar o REA em um repositório, site, blog.

6. Divulgar o REA produzido na escola, entre os amigos e em redes sociais.

$\mathrm{Na}$ figura 3, sistematizamos em formato gráfico um roteiro identificando pelo menos oito ações necessárias no processo de produção e compartilhamento de REA.

\section{Figura 3. Orientações para produzir REA}

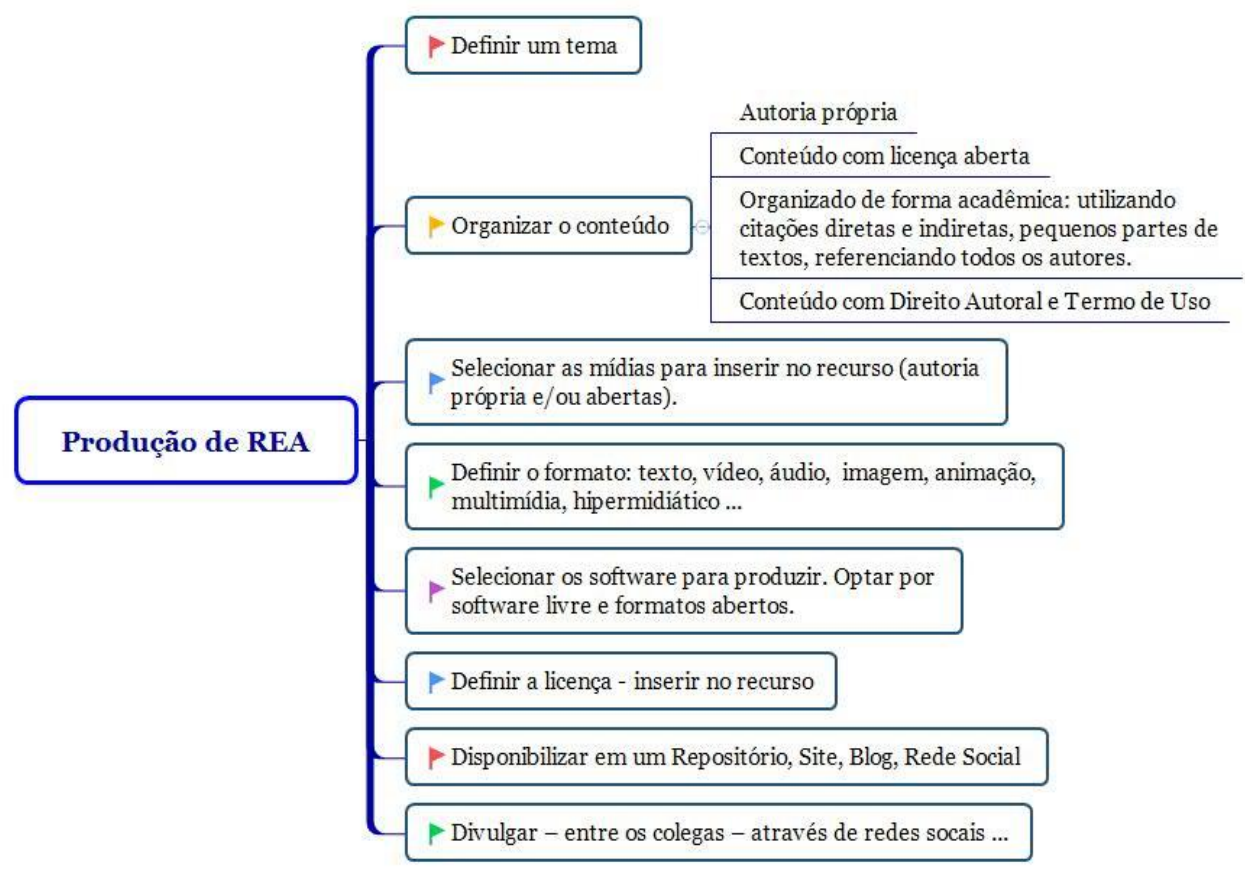

Fonte: As autoras.

Ao compartilhar essas orientações (Figuras 2 e 3) com professores do Ensino Médio, percebemos o potencial nos processos para adaptar e produzir REA. Como movimento da pesquisaação, encontramos, na sistematização dos roteiros, uma estratégia didático-metodológica que baliza e parametriza tanto a autoria quanto a coautoria. Nessa perspectiva, apostamos nas práticas formativas a respeito de REA como alavancas para o desenvolvimento profissional docente, ou seja, remover as pedras do ensino tradicional e mecanicista, como dizíamos anteriormente. Ao autorar e coautorar REA, os professores do Ensino Médio podem trabalhar a língua materna como organismo vivo, cultural, dinâmico, dialógico explorando todas as funções comunicativas da linguagem e envolvendo os estudantes em movimentos interativos de produção e negociação de sentidos. 


\section{REA PARA O ENSINO DA LÍNGUA MATERNA NO ENSINO MÉDIO: ANALISANDO RESULTADOS E TECENDO REFLEXÕES}

Em ciclos espiralados de pesquisa-ação, desenvolvemos, no primeiro e no segundo semestre de 2016, em duas edições, o SOOC denominado REA: Educação para o futuro, com professores do Ensino Médio, das redes públicas estadual e federal do Rio Grande do Sul. Optamos pelo SOOC por ser uma das novas tendências dos Massive Open Online Course (MOOC)(CHAUHAN, 2014), no qual o número de participantes é menor que nos MOOC, o que possibilita o acompanhamento de um professor ou tutor. A designação SOOC foi criada por Ross (2012) e, embora o curso seja planejado para um público-alvo ou sobre um tema específico, a inscrição é aberta.

Todo o material didático das práticas formativas do SOOC foi organizado com REA disponíveis e produzidos pela equipe de professores do curso. Tais características estão alinhadas com os princípios dos REA. Ademais, o curso, nesse formato, potencializou interação entre professores de diferentes localidades e contextos educacionais, o que viabilizou a socialização dos limites e desafios por eles enfrentados tanto no componente curricular de língua portuguesa quanto em outros. Possibilitou, também, o compartilhamento de relatos de experiências positivas e promissoras de práticas pedagógicas. Já, no campo dos REA, além da compreensão do conceito, potencializou a autoria através da produção de materiais abertos, e a coautoria por meio da adaptação de outros REA.

Tudo isso sustentado no diálogo, na interação mediada pelas tecnologias em rede. No curso da interação, produzimos saberes de modo colaborativo - essência da pesquisa-ação. Na linha que defendemos, essa tipologia de pesquisa constitui-se de atos teórico-práticos sociais e colaborativos, sustentados no diálogo e empreendidos "por participantes em situaciones sociales com objeto de mejorar la racionalidad y la justicia de sus prácticas sociales o educativas, así como su comprensión de essas prácticas y de la situaciones em que éstas tienen lugar" (KEMMIS; MCTAGGART, 1988, p. 9). Nesse processo, temos de um lado, nós, professoras de cursos de formação de professores e pesquisadoras na linha de práticas escolares e políticas públicas; do outro lado, temos professores do Ensino Médio planejando e desenvolvendo práticas escolares. Ambos com um único objetivo: qualificar as ações pedagógicas na Educação Básica. Isso legitima nossa escolha tipológica de pesquisa tendo em vista que num contexto mais amplo de atuação docente e pesquisa acadêmica, o SOOC com professores do Ensino Médio é uma das frentes de atuação dialógica e problematizadora do grupo de estudos.

Como já mencionamos, muitos REA foram produzidos e adaptados para diferentes áreas do conhecimento, uma vez que o curso foi destinado a professores de todas as áreas do Ensino Médio. 
Da língua portuguesa - nosso recorte temático -, obtivemos produções de 14 (quatorze) professores, somando as duas edições ofertadas. Dessas produções, selecionamos, para análise, um planejamento didático, haja vista que o julgamos um exemplar convergente com os questionamentos, os desafios e as possibilidades de ensino da língua materna sobre os quais argumentamos até aqui. Diante disso, tecemos algumas reflexões tendo como fio condutor a problematização inicial, apresentada ainda na introdução deste artigo, que tem nos movido ao longo da escrita: em que medida podemos potencializar práticas de ensino reais e autênticas da língua materna através de REA? Como somos seres dialógicos, outras questões foram surgindo enquanto produzíamos este artigo. Todas elas visando a um mesmo fim: ensino da língua materna na dimensão interacional.

Partindo do que nos move nesta pesquisa, analisemos o REA - planejamento didático - cujo foco é a produção do gênero textual escrito história em quadrinhos, nos softwares livres Gimp e Inkscape. As sequências didáticas de atividades são relativas a sete aulas, contemplando as etapas de planejamento, escrita, reescrita do gênero, estratégias de leitura e estudo de nomenclatura gramatical. Pelo cabeçalho do planejamento (Figura 4), observamos que há o título da aula, abarcando o gênero textual em questão, e, dentro da tabela, está o tema da aula: gêneros textuais. Se o foco do ensino da língua materna é trabalhar o seu potencial interativo, comunicativo, há outra forma de trabalhar linguagem, na dimensão interacional, sem os gêneros textuais? Ou ainda, há comunicação sem eles?

Figura 4. Cabeçalho do planejamento didático - REA.

Curso REA: Educação para o Futuro

Estrutura da Aula com REA

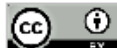

1. Título da Aula: PRODUZINDO HISTÓRIA EM QUADRINHOS COM SOFTWARE-LIVRE

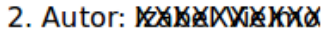

3. Estrutura Curricular

\begin{tabular}{|l|l|l|}
\hline $\begin{array}{c}\text { Modalidade/Nível de } \\
\text { Ensino }\end{array}$ & \multicolumn{1}{|c|}{$\begin{array}{c}\text { Componente } \\
\text { Curricular }\end{array}$} & \multicolumn{1}{|c|}{ Tema } \\
\hline Ensino Médio & $\begin{array}{l}\text { Língua } \\
\text { Portuguesa }\end{array}$ & Gênero Textual \\
\hline
\end{tabular}

Fonte: REA produzido no curso Educação para o futuro, disponível em: https://goo.gl/TJXShL

Notemos que, muitas vezes, em nossas práticas, a intencionalidade é de fato trabalhar forma e função da linguagem, mas a "pedra do ensino tradicional" está sempre no meio do caminho porque os projetos pedagógicos e os componentes curriculares são assim estruturados. Embora tenhamos orientações curriculares nacionais para o Ensino Médio organizadas por temas e por áreas 
do conhecimento, conforme referenciados nas sessões anteriores, os saberes específicos quase sempre são salientes.

Ao desenvolver coautoria de REA o professor do Ensino Médio deve questionar qual o objetivo de produzir um texto? A esse objetivo que o tema deve se referir. O como, o quando, o para quem vêm depois de definido o objetivo da escrita. O primeiro passo é planejar. Isso implica ter uma finalidade e, a partir dela, definir o restante. Escrever denota, portanto, produzir determinado gênero textual, neste caso, a história em quadrinhos. À escrita do gênero agregam-se leitura, análise linguística, uso e reflexão de/sobre elementos notacionais etc. Forma e função são contempladas. Na figura que segue (Figura 5), temos os objetivos do planejamento, no qual podemos observar essa preocupação da professora.

Figura 5. Objetivos do planejamento didático - REA.

O que o aluno poderá aprender com esta aula (objetivos):

- Introduzir o significado de história em quadrinhos, despertar o interesse do aluno, e conhecer os diferentes tipos de HQ e também charge, cartum e tira.

- Ler e compreender textos de HQ com a ajuda do professor (imagem texto verbal e seus elementos: quadrinhos; balões; personagens; onomatopeias; recursos visuais, estrutura (introdução, desenvolvimento e finalização).

- Revisar as Classes Gramaticais - substantivo-adjetivo-artigo-numeralpronome-verbo-conjunção-interjeição-preposição- advérbio.

- Interpretar texto com auxílio de material gráfico diverso (propagandas, quadrinhos, foto, etc.);

- Observar para levantar dados, descobrir informações nos objetos, acontecimentos, situações, etc. e suas representações, usando sites de busca e visualizador de vídeo;

- Aplicar relações já estabelecidas anteriormente ou conhecimentos já construídos a contextos e situações diferentes;

- Aplicar fatos e princípios a novas situações, para tomar decisões, solucionar problemas, etc., utilizando como auxílio um editor de imagem;

- Observar e criar os diferentes tipos de balões, letreiros, novos personagens e onomatopeias, no Laboratório de Informática da Escola;

- Criar uma história em quadrinho usando os softwares gráficos GIMP ou Inkscape.

Fonte: REA produzido no curso Educação para o futuro, disponível em: https://goo.gl/TJXShL - Destaques em vermelho (grifos nossos).

Os destaques em vermelho (grifos nossos) elucidam a ideia de envolver os estudantes no uso real da língua, através da produção de um gênero específico, considerando suas particularidades. Isto é, adequando-se às especificidades da história em quadrinhos, quanto ao estilo, à estrutura, aos recursos linguísticos e extralinguísticos necessários à produção de sentidos e seus efeitos. Outro ponto que demonstra a intenção de uso real e social é a proposição - ação planejada para as aulas 5, 6 e 7 (Figura 8) - de expor as histórias em quadrinhos na escola, a fim de que todos os estudantes tenham acesso e, como a própria professora menciona, sejam incentivados à leitura e à criatividade. Nesse sentido, se o planejamento for desenvolvido, os estudantes escreverão para alguém, ou seja, 
existirá o outro, o interlocutor/leitor com o qual irão interagir. Não será uma escrita em que não há ninguém do outro lado texto.

Essa proposição, portanto, abarca o uso real da língua materna. No caso do exemplar em análise, abarca ainda mais porque essa produção está compartilhada em rede (na internet) com licença aberta, ou seja, como REA. O alcance de público/leitores é maior, e outras ideias poderão ser agregadas à história em quadrinhos, uma vez que, para ser de fato REA, a licença tem de permitir adaptações. Além da autoria promovida nessa produção inicial, a coautoria será potencializada no momento em que outras obras forem adaptadas. Esse é um aspecto de destaque desse planejamento didático - REA - em análise, uma vez que está compartilhado na rede (internet) com licença CC BY, ou seja, licença permissiva de adaptação e livre compartilhamento, com garantia dos direitos autorais do produtor original, como também dos coautores. Por ser REA, permite essa flexibilização, corroborando para que ampliemos as possibilidades de uso real e autêntico da língua materna.

As próximas figuras (Figuras 5 e 6) explicitam a sequência de atividades didáticas no decorrer das sete aulas planejadas. Percebemos que, em todas as aulas, o gênero em questão é trabalhado. Desse modo, há tempo didático coerente à realização de todas as etapas da produção textual. Estratégias de leitura também são mencionadas. Ao propor que os estudantes antecipem as ações, os acontecimentos da história, permitido que formulem hipóteses (Figura 5 - aula 3), está explorando os seus conhecimentos prévios através da pré-leitura. Ao confirmarem ou refutarem as hipóteses, estarão estabelecendo interação com autor e texto. Essa interação sustentará a produção de sentidos, a interpretação textual. Explorando, desse modo, o desenvolvimento da habilidade leitora.

Figura 5. Aulas 1, 2, 3 e 4 do planejamento didático - REA.

\section{Aula 1:}

0 professor deve iniciar essa aula, usando o datashow, onde será introduzido, o tema, a partir do video - 0 que sào Quadrinhos? hittps:/lyoutu be/kP8LNUS6 68U

0 professor pedirá que os alunos anotem no cademo o que mais thes chamou atençăo, para posterior discussăo em sala de aula.

\section{Aula 2:}

Na sala de aula, o professor deverá trazer diferentes gibis, onde apresentará aos alunos 0 género textual: história em quadrinhos. Logo após os alunos deverão escrever quais săo os seus personagens favoritos e 0 que gostam más em um gibi Solicitar que os alunos identifquem quais sâo as classes gramaticais mencionadas nas revistas.

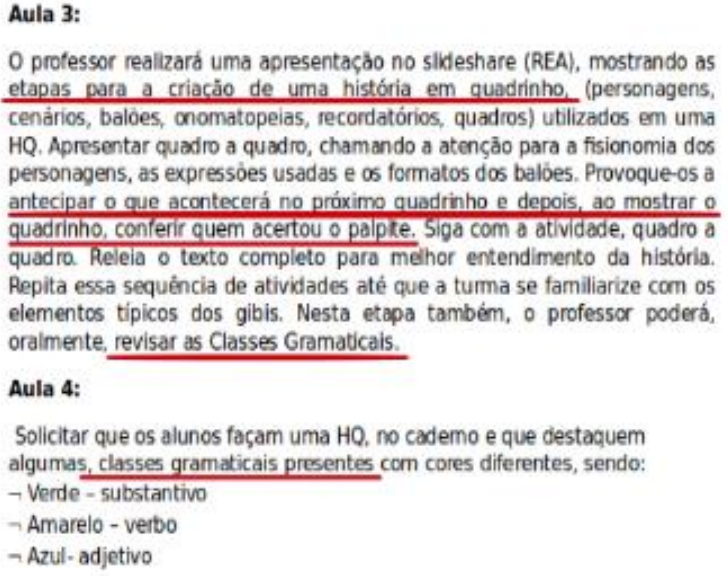

$\neg$ Azul-adjetivo

Fonte: REA produzido no curso Educação para o futuro, disponível em: https://goo.gl/TJXShL - Destaques em vermelho (grifos nossos) 
O ensino da gramática, parece-nos, que está focado no ensino de nomenclaturas. Em que contribui para a ampliação da competência linguística identificar e destacar as classes gramaticais no texto, sem compreender a funcionalidade e os efeitos que produzem? Para Antunes (2009, p. 239), um desafio à ser superado é “o de confundir regras de gramática com nomenclatura gramatical. Na verdade, os professores nem se fixam muito nas regras de gramática. Fixam-se, isso, sim, na nomenclatura, na classificação gramatical, na definição das classes, com todas as suas subdivisões." "O objeto de estudo deve ser o texto, não, a gramática. A gramática é um dos vários componentes do texto. Estuda-se gramática, porque, para se entender um texto, precisa-se de gramática. Já disse que não existe língua fora do texto; também não existe gramática fora do texto.” (ANTUNES, 2009, p. 238).

Figura 6. Aulas 5, 6 e 7 do planejamento didático - REA

\title{
Mulas 5,6 e 7:
}

\begin{abstract}
Após toda a preparação, os alunos irão ao Laboratório de Informática, o professor apresentará os recursos dos softwares educativos GIMP e Inkscape, onde cada aluno deverá produzir sua $\mathrm{HQ}$.

Nessa atividade o importante é que os alunos estarão utilizando-se da leitura e da escrita com uma funçăo social clara, o que os motivará e os auxiliará a perceber a importância de tais conhecimentos.

O professor deverá depois de corrigida cada história, imprimir o resultado dos quadrinhos produzidos e elaborar, com ajuda dos alunos, uma exposição de todas as histórias produzidas, incentivando a leitura e a criatividade de todos os alunos da escola.

Para finalizar a atividade, os alunos produzirão um texto coletivo, sistematizando as descobertas e as experiências vividas no laboratório de informática.
\end{abstract}

Fonte: REA produzido no curso Educação para o futuro, disponível em: https://goo.gl/TJXShL - Destaques em vermelho (grifos nossos)

Embora, em muitos aspectos, o planejamento didático licenciado como REA contemple a dimensão interacional da linguagem, há alguns pontos que poderão ser reformulados em versões futuras. Essa é justamente uma das maiores vantagens dos REA: incontáveis versões poderão ser criadas ampliando, reformulando, recortando, remixando aspectos dos conteúdos.

Analisando o enunciado de produção textual apresentado na última aula (Figura 8), temos a informação de que os "alunos produzirão um texto coletivo, sistematizando as descobertas e as experiências vividas no laboratório de informática". Bem, parece-nos que se trata de tipologia textual narrativa, com espaço para descrição, exposição, já que se trata de abordar as experiências vivenciadas, os fatos ocorridos. Nesse item, não está enunciado qual gênero textual produzir. Outro professor de língua portuguesa poderá explicitar isso numa próxima versão do REA compartilhado. Do mesmo modo, diante da finalidade: "sistematizar as descobertas e as experiências vividas no laboratório de informática" é necessário delimitar e priorizar para quem escrever. Há muitos 
aspectos no exercício potente da autoria e coautoria de REA de língua portuguesa para o Ensino Médio sobre os quais precisamos refletir, discutir nos cursos de formação professores, nas atividades de pesquisa no âmbito acadêmico, escolar, nas atividades de extensão, a fim de que continuemos produzindo e compartilhando práticas pedagógicas abertas que visem ao potencial interativo e comunicativo da linguagem.

Em destaque na nossa análise, no escopo dos REA, percebemos o cuidado da professora em contemplar o princípio de abertura na elaboração do planejamento didático. Isso porque além de contribuir para a cultura livre a partir da atribuição da licença CC mais permissiva (possibilita adaptações, uso comercial da obra e compartilhamento sob qualquer licença), menciona, nas sequências de atividades propostas, também a utilização de softwares livres. Os softwares livres estão em lógica semelhante à dos REA, pois visam à promoção da cultura do compartilhamento livre para utilização, estudo, modificação e redistribuição da tecnologia do software. No movimento REA, nem sempre há obrigatoriedade das novas versões serem compartilhadas novamente sob a mesma licença aberta. Existe a orientação para observar a compatibilidade das licenças entre os REA originais e adaptados ou remixados. Nesse requisito, defendemos que, para ser REA, a licença sempre tem de permitir adaptações. No movimento software livre, o acesso ao código-fonte é garantido pela licença adotada, ou seja, permanece sempre a abertura, independentemente da quantidade de modificações. Nesse sentido, o REA para o ensino de língua portuguesa em análise elucida um fazer coerente com o pensar certo do movimento REA, contemplando os princípios basilares de abertura.

\section{RESSIGNIFICANDO PALAVRAS NA PRODUÇÃO DE SENTIDOS, TECEMOS NOSSAS CONSIDERAÇÕES FINAIS}

No âmbito das produções didáticas abertas, como democratização de práticas de ensino da língua materna no Ensino Médio para além da memorização de regras e nomenclaturas gramaticais, algumas premissas são importantes:

a) é imprescindível consolidar tanto a abertura técnica quanto a abertura legal dos recursos educacionais. Os livros didáticos e outros materiais impressos continuam tendo papel significativo no processo ensino-aprendizagem da língua materna no Ensino Médio. No entanto, em tempos de convergência de mídias e modificação cultural das dinâmicas de comunicação e interação mediadas pelas tecnologias digitais, os professores do Ensino Médio precisam tanto ter livre acesso quanto permissão para readaptar os materiais didáticos, retemporalizando-os e recontextualizando-os; 
b) se a linguagem é um lugar de interação comunicativa que nos constitui nos diferentes domínios sociais, a autoria e a coautoria de REA poderá potencializar intercâmbios culturais e internacionalização do trabalhos de professores do Ensino Médio. Nesse sentido, a publicação e o compartilhamento das produções elaboradas pelos professores precisa ser cada vez mais otimizada por meio da indução de políticas públicas que gerem desenvolvimento profissional. Um dos caminhos viáveis-possíveis é incentivar e fomentar a criação, manutenção e atualização constante de repositórios públicos e compartilhamento de obras em domínio público;

c) desenvolver programas de formação continuada e aprendizagem ao longo da vida é essencial para aprimoramento da fluência tecnológico-pedagógica requerida dos professores do Ensino Médio. Para tanto, a dinâmica dos ciclos espiralados de pesquisa-ação sustentadas pela implementação de cursos no formato SOOC tematizado por (co)autoria de REA gera comunidades autênticas de estudos, elaborações didáticas livres e abertas, pesquisas e produção do conhecimento educacional na interface dialética entre teoria-prática-teoria. O conhecimento do conteúdo específico de um componente curricular não é o suficiente para consolidarmos língua materna no Ensino Médio na dimensão interacional que almejamos. Por isso, é imprescindível que o professor do Ensino Médio seja fluente tanto no conhecimento pedagógico quanto tecnológico;

d) a criação de dispositivos didático-metodológicos que sistematizam princípios e operações nas etapas de criação e cocriação de REA gera como resultados a elaboração de planejamentos didáticos potentes para o desenvolvimento de interlocutores competentes linguística e discursivamente em movimentos interativos de produção e negociação de sentidos. Nesse contexto, (co)autoria de REA potencializa práticas pedagógicas no Ensino Médio que integram forma e função no uso da linguagem.

\section{REFERÊNCIAS}

ALMEIDA, Milton José. Ensinar português? In: GERALDI, João Wanderley. (Org.). O texto na sala de aula. São Paulo: Ática, 2006.

AMIEL, Tel. Recursos Educacionais Abertos: uma análise a partir do livro didático de história. Revista História Hoje. v. 3, n. 5, p. 189-205. 2014. Disp.: 〈https://rhhj.anpuh.org/RHHJ/article/view/128>. Acesso em: 15 nov. 2016.

ANDRADE, Carlos Drummond. Poesia e prosa. Rio de Janeiro: Nova Aguilar, 1988.

Biografia de um poema. Rio de Janeiro: Editora do Autor, 1967.

ANTUNES, Irandé. Aula de português: encontro e interação. São Paulo: Parábola Editorial, 2003.

ANTUNES, Irandé. Ensino de Língua Portuguesa: repercussões educacionais, políticas e socioeconômicas. Conjectura. Caxias do Sul, v. 14, n. 2, p. 231-240, maio/ago. 2009. Disp.: <http://www.ucs.br/etc/revistas/index.php/conjectura/article/ download/46/43>. Acesso em: 20 nov. 2016.

BATES, A. W. (Tony). (2015). Teaching in a Digital Age. Disp.: < https://opentextbc.ca/teachinginadigitalage/. Acesso em 30 out. 2016 
BUTCHER, N. Basic Guide to Open Educational Resources. British Columbia/Paris: COL e UNESCO, 2011. Disp.: <http://www.unesco.org/new/fileadmin/MULTIMEDIA/HQ/CI/CI/pdf/publications/basic guide_oer_pt.pdf $>$. Acesso em: 10 nov. 2016

BAKHTIN, Mikail. Estética da criação verbal. Trad.: Paulo Bezerra. São Paulo: Editora WMF Martins Fontes, 2011.

BRASIL. Ministério da Educação. Secretaria de Educação Fundamental. Parâmetros Curriculares Nacionais: Língua Portuguesa ( $1^{\circ}$ ao $4^{\circ}$ ciclo do Ensino Fundamental). Brasília: MEC, 1997.

STMT. Parâmetros Curriculares Nacionais para o Ensino Médio. Brasília: MEC, 2000.

MEC/SEMT. PCN Ensino Médio Orientações Educacionais Complementares aos Parâmetros Curriculares Nacionais. Brasília: MEC, 2000 b. 2006. $239 \mathrm{p}$

MEC/SEB. Linguagens, códigos e suas tecnologias / Orientações curriculares para o ensino médio. Brasília,

MEC/CNE/CEB. Resolução n. 2, de 30 de janeiro de 2012 - Define Diretrizes Curriculares Nacionais para o Ensino Médio. Brasília, 2012.

BORTONI-RICARDO, Stella Maris. Educação em língua materna: a sociolingüística na sala de aula. São Paulo: Parábola Editorial, 2004.

CHAUHAN, Amit. Massive Open Online Courses (MOOCS): Emerging Trends un Assessment and Accreditation. In Digital Education, n.25, 2014. Disp.: 〈http://revistes.ub.edu/index.php/der/article/view/11325〉. Acesso: 15 out. 2016.

FARACO, Carlos Alberto. Português: língua e cultura. Curitiba: Base, 2005.

FIORIN, José Luiz. Elementos de análise do discurso. São Paulo: Contexto, 2014.

FRANCHI, Carlos. Criatividade e Gramática. São Paulo. Secretaria de Estado da Educação de São Paulo. Coordenadoria de Estudos e Normas Pedagógicas - CENP, 1988.

FREITAS, Olga. Equipamentos e materiais didáticos. Brasília: Universidade de Brasília, 2007.

KEMMIS, S.; MCTAGGART, R. Cómo planificar la investigación-acción. Barcelona: Editorial Laertes, 1988.

KOCH, Ingedore Villaça. O texto e a construção dos sentidos. São Paulo: Contexto, 2014.

MALlMANN, E. M.; NOBRE, A. Dos Objetos de Aprendizagem aos Recursos Educacionais (Abertos). In: Atas Challenges: Meio Século de TIC na Educação. Half a Century of ICT in Education. Braga, 2015.

MARCUSCHI, Luiz A. Produção textual, análise de gêneros e compreensão. São Paulo: Parábola Editorial, 2008.

MOTA, Ronaldo. Reforma do Ensino Médio. Disponível em: <http://www.clipnaweb.com.br/estacio/Imagens/2016\% 5C11\%5C26\%5C0000061274.pdf>. Acesoo em 27 nov. 2016.

RICHTER, Marcos Gustavo. Ensino do português e interatividade. Santa Maria: Editora da UFSM, 2000.

ROSS, H. Instead of a MOOC, How About a SOOC? Disp.: <http://words.usask.ca/gmcte/2012/10/29/instead-of-amooc-how-about-a-sooc/>. Acesso em: 22 nov. 2016

SANTOS, A. I. Educação aberta: histórico, práticas e o contexto dos recursos educacionais abertos. In: SANTANA, Bianca; ROSSINI, Carolina; PRETTO. Nelson De Lucca. (Org.). Recursos Educacionais Abertos: práticas colaborativas políticas públicas. Salvador: Edufba; São Paulo: Casa da Cultura Digital, 2012. 246 p. Disponível em: <http://www.artigos.livrorea.net.br/>. Acesso: 12 nov. 2016

SEBRIAM, Débora; GONSALES, Priscila. Inovação Aberta em Educação - Conceitos e modelos de negócios. CIEB Estudos, 2016. Disponível em: 〈http://educadigital.org.br/estudocieb/o-estudo/>. Acesso em: 30 nov. 2016

TEZZA, Cristóvão. Material Didático: um depoimento. In: Educar em Revista. Curitiba, PR: Editora UFPR, n. 20, p 35-42, jul./dez. 2002. Disp.: <http://www.cristovaotezza.com.br/textos/palestras/p_materialdidatico.htm.>. Acesso em: 28 nov. 2016.

UNESCO. Declaração REA de Paris. Disponível em: <http://www.unesco.org/new/fileadmin/MULTIMEDIA/ HQ/CI/CI/pdf/Events/Portuguese_Paris_OER_Declaration.pdf $>$. Acesso em: 10 nov. 2016

UNESCO. Diretrizes para os Recursos Educacionais Abertos no Ensino Superior. 2015. Disponível em: <http://unesdoc.unesco.org/images/0023/002328/232852por.pdf>. Acesso em: 29 nov. 2016.

WILEY, D. A. (2014). The access compromise and the 5th R. Disp.: 〈http://opencontent.org/blog/archives/3221>. Acesso em: 09 out. 2016. 


\section{RESUMO}

A linguagem, lugar de interação comunicativa, constitui-nos nos diferentes domínios sociais. O propósito é impulsionar produções didáticas abertas, no âmbito técnico e legal, democratizadoras de práticas de ensino da língua materna no Ensino Médio para além da memorização de regras e nomenclaturas gramaticais. Em ciclos espiralados de pesquisa-ação, desenvolvemos Small Open Online Course (SOOC) tematizado por (co)autoria de Recursos Educacionais Abertos (REA). Os resultados apontam planejamentos didáticos para o desenvolvimento de interlocutores competentes linguística e discursivamente, em movimentos interativos de produção e negociação de sentidos. Conclui-se que a (co)autoria de REA potencializa práticas pedagógicas no Ensino Médio que integram forma e função no uso da linguagem.

Palavras-chave: Linguagem e interação. Recursos Educacionais Abertos. Ensino Médio.

\section{ABSTRACT}

The language, place of communicative interaction, constitutes us in the different social domains. The purpose is to promote open didactic productions, in the technical and legal scope, democratizing practices of teaching the mother tongue in High School in addition to memorizing rules and grammatical nomenclatures. In spiral cycles of action research, we developed Small Open Online Course (SOOC) thematized by (co) authorship of Open Educational Resources (OER). The results point to didactic planning for linguistic and discursive development of competent interlocutors in interactive production and negotiation of meanings. It is concluded that the (co) authorship of OER enhances pedagogical practices in High School that integrate form and function in the use of language.

Keywords: Language and interaction. Open Educational Resources. High school. 